\title{
Hemophagocytic Lymphohistiocytosis in a Pediatric Patient
}

\author{
Saad Waheed and Saima Gillani \\ Department of Pediatrics, Ayub Teaching Hospital, Abbottabad, Pakistan
}

\begin{abstract}
Hemophagocytic Lymphohistiocytosis (HLH) is an uncommon but a potentially fatal disease characterised by high grade fever, hepato-splenomegaly, deranged liver functions, cytopenias and multi-organ involvement. HLH has its own diagnostic criteria, which comprise of various clinical and laboratory features, which were revised in 2004 by HLH Society for prompt identification and recognition. Here, we present a case of 9-year developmentally normal female with all the complaints as mentioned above, who received treatment for almost eight months as a case of pyrexia of unknown origin (PUO) without a definitive diagnosis. The differential diagnosis of HLH was considered in the patient and later, it was corroborated by hemophagocytic activity on bone marrow aspiration examination. The diagnosis of HLH was made after fulfillment of its criteria which was addressed completely and found veracious. After addressing the active complaints of the patient, she was referred to a pediatric oncologist for chemotherapy and further management; and counselled for hematopoietic stem cell transplantation (HSCT).
\end{abstract}

Key Words: Hemophagocytic lymphohistiocytosis, Pyrexia of unknown origin (PUO), Pediatric hematopoietic stem cell transplantation.

How to cite this article: Waheed S, Gillani S. Hemophagocytic Lymphohistiocytosis in a Pediatric Patient. J Coll Physicians Surg Pak 2021; 31(08):975-977.

\section{INTRODUCTION}

Hemophagocytic Lymphohistiocytosis (HLH) was described for the first time in 1952 by James Farquhar and Albert Clarieaux with features of pancytopenia, hepato-splenomegaly, and nonresolving high grade fever. ${ }^{1} \mathrm{~A}$ life-threatening rare syndrome of immune system disarrays that leads to multi-organ failure due to the hyperactivity of cytokines and macrophages. ${ }^{2} \mathrm{HLHis}$ a hyperactive inflammatory state resulting in release of activated lymphocytes and histiocytes, which cause tissues destruction and shares some similarities with the macrophage activation syndrome. ${ }^{3,4}$

The activated macrophages engulf one's own hematopoietic stem cells and various blood cells as evident upon biopsies of bone marrow, liver, spleen etc.; hence, the name haemophagocytosis. ${ }^{5}$ It basically presents in two forms: a genetic (familial $\mathrm{HLH}$ ) form and an acquired form secondary to infections, mostly,viral, acquired immune deficiency syndromes, auto-inflammatory diseases, auto-immune diseases and malignancies. $\mathrm{HLH}$ in children has a strong association with family history. Familial HLH is more frequently found in infants, but cases of infection-associated $\mathrm{HLH}$ are also encountered.

Correspondence to: Dr. Saad Waheed, Department of Pediatrics, Ayub Teaching Hospital, Abbottabad, Pakistan E-mail: khana726@gmail.com

Received: October 04, 2019; Revised: November 09, 2019; Accepted: November 21, 2019

DOI: https://doi.org/10.29271/jcpsp.2021.08.975
Overall incidence of HLH is approximately 1.2 cases per $1,000,000$ individuals annually. ${ }^{6}$ Familial HLH (patients less than one year of age) comprises $70-80 \%$ of these. ${ }^{7}$ Hematologic and malignancies-associated $\mathrm{HLH}$ occur more commonly in adult group. The variable features and rarity of this disease make timely diagnosis and intervention difficult, thus resulting in a deadly outcome.

\section{CASE REPORT}

A 9-year unvaccinated child, born from consanguineous marriage, with growth parameters all falling below 5th centile, presented to us with high grade fever up to $102^{\circ} \mathrm{F}$, mild abdominal distention and bilateral pedal edema for the last eight months. Fever was high grade, continuous but not associated with rigors and chills. Patient was prescribed previously paracetamol, penicillin (amoxicillin), aminoglycosides (amikacin), various $2^{\text {nd }}$ and $3^{\text {rd }}$ generation cephalosporins (cefuroxime, cefotaxime, ceftrioxone) and oral anti-malarials, but was nevercured completely with these medications. According to parents, they had multiple consultations and patient was admitted thrice for same complaints during the last eight months. She also had history of respiratory tract infections. On general physical examination, there was pallor, mildly icteric sclerae and jaundiced skin, a high fever but no lymphadenopathy was noted. There was no clubbing of nails or koilonychia. A high pulse volume was present. Edema was bilateral; it was non-pitting and was restricted up to ankles. Cardiovascular and respiratory systems were normal except for tachycardia with normal vesicular breathing. Furthermore, the patient was completely oriented, active and alert with 
Glasgow coma scale (GCS) of 15/15 with normal power, tone, and reflexes in all limbs. On inspection of abdomen, there was no scar or striate, but mild distention was noted. Bowel sounds were normal on auscultation. On palpation, there was hepato-splenomegaly, liver span being $8 \mathrm{cms}$ and spleen $11 \mathrm{cms}$ below costal margin, but no shifting dullness was noted. Abdominal examination helped us to make various differential diagnoses like leukemia, chronic liver disease, visceral leishmaniasis and $\mathrm{HLH}$. Basic investigations were sent, along with tuberculosis (TB) and visceral leishmaniasis work-up. At first, the complete blood count revealed bicytopenia, hemoglobin was $7.2 \mathrm{~g} / \mathrm{dl}$ (normal $=11-12 \mathrm{~g} / \mathrm{dl}$ ), platelets were $67,000 / \mu \mathrm{L}$ (Normal $\left.=150-400 \times 10^{9} / \mathrm{L}\right)$ and total leukocyte count (TLC) was $7.1 \times 10^{9} / \mathrm{L}$ (normal $=4.5$ to $\left.11.0 \times 10^{9} / \mathrm{L}\right)$.

In addition, differential leucocyte count (DLC) showed lymphocytosis, i.e., 68\% (normal = 20 - 40\%). Moreover, blood cultures returned indecisively. Inflammatory markers of ESR $\left(70 \mathrm{~mm} / 1^{\mathrm{st}} \mathrm{hr}\right)$ and CRP $(>3.0 \mathrm{~g} / \mathrm{L})$ were raised but there were no visceral leishmania antibodies. Gene expert of gastric aspirate for TB was negative with normal chest x-ray and negative Monteux test. Liver functions tests were impaired: serum total bilirubin was $5.9 \mathrm{mg} / \mathrm{dl}$ (indirect, $2.8 \mathrm{mg} /$-dl), alkaline phosphate was 950u /-L with normal ALT and renal function tests. In addition, hepatitis B, C and HIV testing was negative. Ultrasound abdomen showed hepato-splenomegaly with normal echo texture. The patient was given broad spectrum antibiotics, IV ceftrioxone $1 \mathrm{gm}$ (BD) and IV quinine (5 days) with oral paracetamol for fever. On third day of admission, she started improving, butthere waslow-grade intermittentfeverand hepato-splenomgaly was increasing each day and there was appearance of small petechial spots on her right leg. Complete blood count (CBC) was repeated, bicytopenia was converted to pancytopenia $(\mathrm{Hb}=6.9 \mathrm{~g} / \mathrm{dL}$, platelets $=37,000 / \mu \mathrm{L}$ and $\mathrm{TLC}=3.8 \times$ $\left.-10^{9} / \mathrm{L}\right)$. On $6^{\text {th }}$ day, bone marrow aspiration was done. After consideration of $\mathrm{HLH}$, serum ferritin and fasting triglyceride levels were also sent, which were significantly high [serum ferritin $=1500 \mathrm{ng} / \mathrm{ml}$ (normal $=$ up to $140 \mathrm{ng} / \mathrm{ml}$ and triglycerides $=424 \mathrm{mg} / \mathrm{dl}$ (normal = less than $150 \mathrm{mg} / \mathrm{dl}$ )], thus supporting the diagnosis of $\mathrm{HLH}$. Whole blood transfusion was done thrice as supportive management. Jaundice improved somewhat. On the $11^{\text {th }}$ day of admission, bone marrow biopsy report was received showing hemophagocytosis with moderate megaloblastic anemia (-started on vitamin B12 and folic acid). The diagnosis of HLH was confirmed after analysis of all clinical signs, symptoms and laboratory tests. Our patient scored 6 points out of total 8 points in the diagnostic protocol of HLH. ${ }^{7}$ The patient was started on oral dexamethasone immediately and referred to a pediatric oncologist for chemotherapy as a case of $\mathrm{HLH}$. We also gave alternative therapy recommendations to parents about the hematopoietic stem cell transplantation (HSCT), which has better prognosis if the resources allow it.

\section{DISCUSSION}

A deadly illness, HLH is a hematological disorder manifested by clinical signs and symptoms of severe inflammation and uncon- trolled activation of the immune system. It is most often characterised by pyrexia of unknown origin (PUO), hepato-splenomegaly and bi- or tri-lineage cytopenias. Moreover, elevated levels of liver enzymes, serum ferritin, serum triglycerides and low levels of fibrinogen are commonly seen in HLH patients. In 35-40 $\%$ of patients, skin manifestations such as a generalised transient maculopapular rash, erythroderma, petechiae and edema appear. ${ }^{8}$ In our patient, the diagnostic criteria for HLH were met as 6 out of the 8 criteria were present. Our patient had no family history of malignancy. Although HLH has basically two forms, the first being a congenital primary or familial form and the second being an acquired or secondary form, clinical presentation and diagnostic criteria for both are identical. The underlying risk for primary $\mathrm{HLH}$ is genetic abnormalities leading to fixed defects in the normal functioning of the cytotoxic T cells. Primary HLH is due to genetic defects in genes (PRF1, MUNC 13-4, STXBP2 and STX11) that are essential to the cytolytic secretion pathway, which enable perforin and granzymes to induce apoptosis in target cells. ${ }^{9}$ Etiology of acquired HLH is multi-factorial and potential causes include infections such as Epstein-Barr virus (EBV), cytomegalovirus (CMV) and herpes simplex virus (HSV). Moreover, autoimmune diseases such as systemic lupus erythematosus (SLE), Kawasaki syndrome and malignancies such as natural killer[ NK] cell leukemia, B and Tcell lymphomas may be the underlying causes in some cases. ${ }^{5,7}$ The pathogenesis of acquired $\mathrm{HLH}$ remains elusive, but heterozygous variations and polymorphisms in familial proteins are commonly seen in patient populations with this type of HLH.

In 1994, the Histiocyte Society devised its first standard definition which was revised in 2004 and proper diagnostic criteria were formulated. ${ }^{10,11}$

Some protocol investigations could not be carried out due to non-availability in our area i.e. natural killer cells activity, CD25 (Interleukin-2 receptor) levels and molecular testing of $\mathrm{HLH}$. Treatment modalities directly target the hyperactivity of the immunesystem (Tcells and histiocytes) by using immunosuppressant drugs and chemotherapy (dexamethasone and etoposide in conjunction with cyclosporine). The HLH-94 trial, comprised of same above mentioned drugs and the HLH mortality plummeted from $95 \%$ to $<30 \%$ ( 8 weeks of etoposide and dexamethasone therapy, followed by maintenance therapy with cyclosporine and pulse therapies of etoposide and dexamethasone). HSCT is also an option for this ailment, but it is mainly for familial $\mathrm{HLH}$ or relapsing $\mathrm{HLH}$ or EBV-associated $\mathrm{HLH}^{12}$ Because of rarity, timely diagnosis of $\mathrm{HLH}$ is often missed in initial workup, especially in primary and secondary healthcare set-ups. It should be considered in the differential diagnosis of PUO. A child with non-resolving and recurring fever should be referred to a tertiary care centre for proper workup. We emphasise early recognition and immediate commencement of treatment for $\mathrm{HLH}$ to reduce the high mortality, associated with this condition, especially in cases of delayed diagnoses.

\section{PATIENT'S CONSENT:}

Informed consent was obtained from the patient's parents. 


\section{CONFLICT OF INTEREST:}

The authors declared no conflict of interest.

\section{AUTHORS' CONTRIBUTION:}

SW: Conceptualisation, patient management and workup, write-up, literature search, proofreading.

SG: Literature search, proofreading.

\section{REFERENCES}

1. Farquhar J, Claireaux A. Familial Haemophagocytic Reticulosis. Arch Dis Child 1952; 27(136):519-25.

2. Ramachandran S, Harlow J, Chan R, Zia S. Initial presentation of hemophagocytic lymphohistiocytosis in a well-appearing child with fevers. Pediatrics 2019 [cited 30 September 2019]. Available from: http://pediatrics. aappublications.org/content/141/1_MeetingAbstract/698

3. Janka GE, Lehmberg K. Hemophagocytic syndromes - An update. Blood Rev 2014; 28(4):135-42. doi: 10.1016/ j.blre.2014.03.002.

4. Ladish S. Histiocytosis syndromes in childhood. In: Kleigman RM, Stanton BF, St Geme JW, et al. Nelson text book of pediatrics. First South Asia edition.Vol.3. India: Elsevier 2015; p.2484-9.

5. Contino A, Trombatore G, Timeus F. Hemophagocytic Lymphohistiocytosis in Pediatric Patients: A Review [Internet]. Scientonline.org. 2019. Available from http:// scientonline.org/open-access/hemophagocytic- lymphohistiocytosis-in-pediatric-patients-a-review.pdf

6. Henter JI, Elinder G, Söder O, Ost A. Incidence in Sweden and clinical features of familial hemophagocyticlympho histiocytosis. Acta Paediatr Scand 1991; 80(4):428-35. doi: 10.1111/j.1651-2227.1991.tb11878.x.

7. Janka GE. Familial and acquired hemophagocyticlymphohistiocytosis. Annu Rev Med 2012; 63:233-46. doi: 10.1146/annurev-med-041610-134208.

8. Ramos-Casals M, Brito-Zerón P, López-Guillermo A, Khamashta MA, Bosch X. Adult haemophagocytic syndrome. Lancet 2014; 383(9927):1503-16. doi: 10.1016/S0140-6736(13)61048-X.

9. Weitzman S. Approach to hemophagocytic syndromes. Hematology Am Soc Hematol Educ Program 2011; 2011: 178-83. doi: 10.1182/asheducation-2011.1.178.

10. Verbsky JW, Grossman WJ. Hemophagocyticlymphohistiocytosis: Diagnosis, pathophysiology, treatment, and future perspectives. Ann Med 2006; 38(1):20-31. doi: 10.1182/asheducation- 2011.1.178.

11. Henter JI, Horne A, Aricó M, Egeler RM, Filipovich AH, Imashuku S, et al. HLH-2004. Diagnostic and therapeutic guidelines for hemophagocytic lymphohistiocytosis. Pediatr Blood Cancer 2007; 48(2):124-31. doi: 10.1002/pbc.21039.

12. Trottestam H, Horne A, Aricò M, Egeler RM, Filipovich AH, Gadner $\mathrm{H}$, et al. Histiocyte Society. Chemo-immunotherapy for hemophagocyticlymphohistiocytosis: Long-term results of the HLH-94 treatment protocol. Blood 2011; 118(17): 4577-84. doi: 10.1182/blood-2011-06-356261. 